convey good protection against systemic emboli (Szekely, 1964). The operation designed to prevent further emboli consists of amputation of the appendix and correction when possible of the valve disease, even though it is trivial. Left atrial appendicectomy was recommended by Madden (1949), but he reported on only two cases, the results were not convincing, and he did not press home his argument.

\section{Summary}

Systemic embolism in patients with mitral stenosis was more than three times commoner when the left atrial appendix was large than when small.

Conversely, the left atrial appendix was larger in patients with a history of embolism than in those without it.

The occurrence of embolism rose steeply in successive decades when the appendix was large but not when it was small.

The left atrial appendix should be amputated at mitral valvotomy as an extra precaution against embolism.
A number of patients presenting with systemic embolism and only slight rheumatic mitral-valve involvement have disproportionate enlargement of the left atrial appendix. Amputation of the appendix and relief of mitral stenosis, however slight, is recommended here as a protection against further emboli.

We are grateful to the physicians and surgeons of the Middlesex and Harefield Hospitals, to Dr. A. Kardalinos, and to Mr. R. F. J. Withers, of the Department of Biology as Applied to Medicine, Middlesex Hospital Medical School, for advice and assistance.

\section{REFERENCES}

Bailey, C. P., Olsen, A. K., Keown, K. K., Nichols, H. T., and Jamison, W. L. (1952). f. Amer. med. Ass., 149, 1085.

Bannister, R. G. (1960). Lancet, 2, 329.

Belcher, J. R., and Somerville, W. (1955). Brit. med. F., 2, 1000.

Graef, I., Berger, A. R., Bunim, J. J., and de la Chapelle, C. E. (1937). Arch. Path., $24,344$.

Madden, J. L. (1949). Э. Amer. med. Ass., 140, 769.

Parmley, L. F. (1962). Circulation, 25, 553 .

Szekely, P. (1964). Brit. med. ₹., 1, 1209.

Williams, W. G. (1963). Brit. Heart Ұ., 25, 637.

\title{
Mitral Stenosis and Systemic Emboli
}

\author{
DAVID LILLICRAP,* M.A., B.M., M.R.C.P.; ALINA PIESOWICZ, $†$ M.B., M.R.C.P., D.C.H.
}

Systemic emboli in patients with mitral stenosis are a common event. In patients with mitral stenosis of all grades of severity Wood (1954) reported an incidence of $14 \%$. Bannister (1960) found that 22 patients out of 114 had systemic emboli over a period of 10 years. All these patients initially had mitral stenosis that was not severe enough to warrant valvotomy.

Mitral valvotomy is performed to relieve significant mechanical obstruction at the valve. If a patient with mitral stenosis has an embolus this is usually accepted as an additional reason for valvotomy. Mitral valvotomies have also been performed in patients in whom the degree of obstruction in itself was not sufficient to warrant operation, but in whom systemic emboli had occurred. It has also been suggested that in patients over the age of 40 who have moderate mitral stenosis but only trivial symptoms the risk of systemic emboli is high and valvotomy should be performed before any emboli occur (Bannister, 1960). This is reasonable only if the risk at operation is small, there is no detrimental effect of operation on the survivors, and the incidence of post-operative systemic emboli is reduced. With this in mind we have followed up 84 patients who had mitral valvotomies at Guy's Hospital in 1957, 1958, and 1959. All patients were over the age of 40 . The number of patients under 40 was too small for any comparisons and they were therefore excluded. We also excluded patients who had significant lesions of other valves and patients who had had previous mitral valvotomies. Six patients had moderate mitral incompetence and eight had slight incompetence. At operation it was confirmed that mitral stenosis was the dominant lesion.

Clinical assessment of disability was made pre-operatively and at yearly intervals, using the grades as defined by Baker

* Senior Registrar, Guy's Hospital, London.

+ Now Senior Registrar, Hospital for Sick Children, Great Ormond Street. London. et al. (1952). These are : grade 0, no disability; grade 1, slight disability ; grade 2 , moderate disability ; grade 3 , severe disability ; and grade 4, total incapacity. Improvement of two or more grades or post-operative grade 0 has been classed under good operative results; no improvement or improvement by one grade as an unsatisfactory result.

Patients are divided into two groups-those without preoperative emboli and those who had pre-operative embolithe occurrence of emboli in all cases being a clinical diagnosis, based on the abrupt onset of symptoms and signs consistent with the occlusion of an artery with rapid partial or complete recovery. The results are reported and compared. All but four patients were seen personally at the three-year follow-up.

\section{Results of Mitral Valvotomy}

\section{Patients Without Pre-operative Emboli}

Of the 84 patients, 48 were in this group. Three died as a direct result of the operation-one in grade 3 died of multiple emboli 24 hours after operation; one in grade 3 died three days after operation from left-sided heart failure, and the third patient was in grade 4 and died of haemorrhagic tracheobronchitis. Table I shows the results of the follow-up in the remaining 45 patients. Thus besides the three opera-

TABle I.-Status of 45 Patients Without Pre-operative Emboli, at Each

\begin{tabular}{|c|c|c|c|c|c|c|}
\hline \multicolumn{3}{|c|}{ Exercise Tolerance } & \multirow{2}{*}{$\begin{array}{c}\text { Pre-op. } \\
0 \\
1 \\
18 \\
26 \\
0\end{array}$} & \multirow{2}{*}{$\begin{array}{c}\text { 1st Year } \\
15 \\
16 \\
7 \\
3 \\
1\end{array}$} & \multirow{2}{*}{$\begin{array}{c}\text { 2nd Year } \\
15 \\
16 \\
4 \\
5 \\
0\end{array}$} & \multirow{2}{*}{$\begin{array}{c}\text { 3rd Year } \\
15 \\
16 \\
3 \\
3 \\
1\end{array}$} \\
\hline $\begin{array}{cc}\text { Grade } & 0 \\
\#, & 1 \\
\# & 2 \\
\# & 3 \\
, & 4\end{array}$ & $\begin{array}{l}. \\
\cdots \\
\cdots\end{array}$ & $\begin{array}{l}\ldots \\
\because \\
\cdots\end{array}$ & & & & \\
\hline Deaths. & $\ldots$ & $\ldots$ & - & 3 & 5 & 7 \\
\hline
\end{tabular}


tive deaths in this group there were three more deaths in the first year and two more in each subsequent year of follow-up. Thus by the end of three years 7 of the 45 patients surviving the operation had died; one of these had been in grade 2 pre-operatively and six in grade 3 . Increased mitral incompetence was the cause of death in five, and the other two patients died in congestive heart failure but details are not available.

In the patients without emboli pre-operatively the result as regards their post-operative exercise tolerance is compared with their pre-operative condition (Table II). In 21 patients exercise tolerance was definitely improved, while 16 patients had unsatisfactory results and one patient was worse at the end of the three-year follow-up. The cause of the unsatisfactory results was increased mitral incompetence in 12 of the 16 , incomplete relief of the stenosis in three, and in one case there was evidence of re-stenosis. The patient who was worse had increased mitral incompetence:

TABLE II.-Patients Without Pre-operative Emboli. Results of Valvotomy on Exercise Tolerance Compared with Their Pre-operative Condition

\begin{tabular}{|c|c|c|c|c|c|}
\hline \multicolumn{3}{|c|}{ Clinical Result } & \multirow{2}{*}{$\begin{array}{c}\text { 1st Year } \\
21 \\
20 \\
1 \\
3\end{array}$} & \multirow{2}{*}{$\begin{array}{c}\text { 2nd Year } \\
21 \\
19 \\
0 \\
5\end{array}$} & \multirow{2}{*}{$\begin{array}{c}\text { 3rd Year } \\
21 \\
16 \\
1 \\
7\end{array}$} \\
\hline $\begin{array}{l}\text { Good . } \\
\text { Unsatisfactory } \\
\text { Deteriorated } \\
\text { Died .. }\end{array}$ & $\begin{array}{l}\ldots \\
\ldots \\
\ldots\end{array}$ & $\begin{array}{l}\ldots \\
\because \\
\cdots\end{array}$ & & & \\
\hline
\end{tabular}

\section{Patients With Pre-operative Emboli}

In this group of 36 patients with pre-operative emboli there were two operative deaths-one patient in grade 1 died on the seventh post-operative day owing to multiple emboli at operation, and one patient in grade 4 died owing to uncontrollable blood loss soon after operation. Tables III and IV show the results in the remaining 34 patients.

TABLE III.-Status of 34 Patients with Pre-operative Emboli, at Each Year of Follow-up

\begin{tabular}{|c|c|c|c|c|c|c|}
\hline \multicolumn{3}{|c|}{ Exercise Tolerance } & \multirow{2}{*}{$\begin{array}{c}\text { Pre-op. } \\
3 \\
9 \\
11 \\
10 \\
1\end{array}$} & \multirow{2}{*}{$\begin{array}{c}\text { 1st Year } \\
7 \\
16 \\
5 \\
3 \\
-\end{array}$} & \multirow{2}{*}{$\begin{array}{c}\text { 2nd Year } \\
7 \\
14 \\
6 \\
3 \\
-\end{array}$} & \multirow{2}{*}{$\begin{array}{c}\text { 3rd Year } \\
6 \\
13 \\
6 \\
4 \\
-\end{array}$} \\
\hline $\begin{array}{cc}\text { Grade } & 0 \\
y & 1 \\
y & 2 \\
y & 3 \\
y & 4 \\
\end{array}$ & $\begin{array}{l}\ldots \\
\ldots \\
\ldots\end{array}$ & $\begin{array}{l}\cdots \\
\cdots \\
\cdots\end{array}$ & & & & \\
\hline Deaths. & $\because$ & $\ldots$ & - & 3 & 4 & 5 \\
\hline
\end{tabular}

TABLE IV.-Patients with Pre-operative Emboli. Results of Valvotomy on Exercise Tolerance Compared with Their Pre-operative Condition

\begin{tabular}{|c|c|c|c|c|c|}
\hline \multicolumn{3}{|c|}{ Clinical Result } & 1st Year & 2nd Year & 3rd Year \\
\hline $\begin{array}{ll}\text { Good } & \ldots \\
\text { Unsatisfactory } & \ldots \\
\text { Deteriorated } & \ldots \\
\text { Died } \quad . & \ldots\end{array}$ & $\begin{array}{l}\ldots \\
\cdots \\
\cdots\end{array}$ & $\begin{array}{l}\ldots \\
\cdots \\
\cdots\end{array}$ & $\begin{array}{r}12 \\
17 \\
2 \\
3\end{array}$ & $\begin{array}{r}11 \\
18 \\
1 \\
4\end{array}$ & $\begin{array}{r}9 \\
18 \\
2 \\
5\end{array}$ \\
\hline
\end{tabular}

The death rate, 5 out of 34 (Table III), is similar in the patients with pre-operative emboli to that in patients without emboli-7 out of 48. The deaths in this group were due to increased mitral incompetence in two patients; mitral restenosis in one, congestive heart failure in one, and multiple systemic emboli in one. Only nine patients had good results (Table IV) at the end of the three-year follow-up, while $18 \mathrm{had}$ unsatisfactory results. Fifteen of the patients with unsatisfactory results had increased mitral incompetence and three had incompiete relief of mitral stenosis.

In the group of patients who were in pre-operative grades 0 and 1 , and therefore had no or minimal disability, mitral valvotomy was performed solely to prevent further systemic emboli. The actual results in this group are similar to those in the group as a whole. At operation the clinical diagnosis of mild stenosis was confirmed. There were 13 of these patients, with one operative death due to multiple emboli. Tables V and VI show the three-year follow-up of the remaining 12 patients.

TABle V.-Status of 12 Patients with Pre-operative Emboli and Minimal Mitral Stenosis at Each Year of Follow-up

\begin{tabular}{|c|c|c|c|c|c|c|}
\hline \multicolumn{3}{|c|}{ Exercise Tolerance } & \multirow{2}{*}{$\begin{array}{c}\text { Pre-op. } \\
3 \\
9 \\
-\end{array}$} & \multirow{2}{*}{$\begin{array}{c}\text { 1st Year } \\
4 \\
6 \\
1 \\
-\end{array}$} & \multirow{2}{*}{$\begin{array}{c}\text { 2nd Year } \\
4 \\
4 \\
2 \\
1\end{array}$} & \multirow{2}{*}{$\begin{array}{c}\text { 3rd Year } \\
4 \\
4 \\
1 \\
1\end{array}$} \\
\hline $\begin{array}{cc}\text { Grade } & 0 \\
, & 1 \\
y & 2 \\
y & 3 \\
\end{array}$ & $\ddot{a}$ & $\begin{array}{l}\ldots \\
\therefore \\
\end{array}$ & & & & \\
\hline Deaths . & 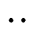 & . & & 1 & 1 & 2 \\
\hline
\end{tabular}

TABLE VI.-Patients with Pre-operative Emboli and Minimal Mitral Stenosis. Results of Valvotomy on Exercise Tolerance Compared with Their Pre-operative Condition

\begin{tabular}{|c|c|c|c|c|c|}
\hline \multicolumn{3}{|c|}{ Clinical Resuit } & 1st Year & 2nd Year & 3rd Year \\
\hline 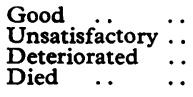 & $\begin{array}{l}\because \\
\therefore \\
\therefore\end{array}$ & $\begin{array}{l}\ldots \\
\therefore \\
\therefore\end{array}$ & $\begin{array}{l}4 \\
5 \\
2 \\
1\end{array}$ & $\begin{array}{l}4 \\
4 \\
3 \\
1\end{array}$ & $\begin{array}{l}4 \\
4 \\
2 \\
2\end{array}$ \\
\hline
\end{tabular}

In this small group of patients, who might have been expected to do well in view of their good pre-operative cardiac condition, two further deaths occurred during the follow-up period. These were due to mitral incompetence and mitral re-stenosis respectively. Only four patients had good results. Four patients had unsatisfactory results and two were worse because of mitral incompetence. These results are not satisfactory and stress the danger of producing or increasing incompetence by operative intervention.

\section{Operative and Post-operative Emboli}

At operation six patients had systemic emboli in spite of the usual operative precautions. Four patients had had previous emboli ; one died and two required embolectomies. Two patients had not had previous emboli ; one of these died, the other required an embolectomy. In the two patients who died the occurrence of emboli had been recognized clinically. Four other patients had systemic emboli one to three years after operation; two had had pre-operative emboli, but two had not. The patients were in grades 2 and 3 pre-operatively, and owing to increased mitral incompetence had had unsatisfactory operative results.

\section{Discussion}

Mitral valvotomy over the age of 40 carries a $6 \%$ operative mortality (Gilchrist, 1963), a figure similar to ours. Our results further show that only $48 \%$ of patients who had no pre-operative emboli had good results at three years, and only $27 \%$ good results were seen in patients who had pre-operative emboli. Even in patients who had pre-operative emboli in the presence of mild mitral stenosis, and who were therefore in pre-operative grades 0 and 1 , good results were seen only in 4 out of $12(33 \%)$. These unsatisfactory results were mainly due to increased mitral incompetence.

There were 34 cases ( $55 \%$ ) of significant mitral incompetence resulting in unsatisfactory results or death. Baker and Hancock (1960) found $21 \%$ significant mitral incompetence and $20 \%$ mild incompetence in their follow-up. While the assessment of mitral incompetence may differ, it is possible that the increased incidence is related to the transventricular approach now in use.

None of the patients who were in grades 0 and 1 preoperatively and had valvotomy to prevent further systemic emboli had post-operative emboli, although one patient died from multiple emboli at operation. In patients in both groups who were in grades 2 and 3 pre-operatively and who were 
not improved by operation further emboli occurred in two, and two had emboli for the first time during the follow-up years. Three patients from grades 2 and 3 who had preoperative emboli and two who had not had pre-operative emboli had emboli at operation. None of the patients who had good operative results had post-operative emboli. Thus, counting both the emboli at operation and during the three follow-up years, 10 of the 84 patients reviewed had emboli (12\%).

Bannister (1960) during an average of 3.4 years' follow-up reported an incidence of systemic emboli of $36 \%$ in patients with mitral stenosis over 40 , and an overall mortality of $5 \%$ ( $1.5 \%$ per year). If our patients did not have mitral valvotomy, 30 patients would have been expected to have emboli over a period of three years (36\%). Our data suggests a reduction in the incidence of post-operative emboli, since 10 patients $(12 \%)$ had further emboli. This is, however, associated with an operative mortality of $6 \%$, a further mortality of $5 \%$ per year, and poor operative results, particularly in the group of patients who were in pre-operative grades 0 and 1 and might have been expected to do well.

Significant mitral stenosis remains the indication for operation. Our results show that the occurrence of systemic emboli is not an additional reason for mitral valvotomy. In patients over 40 who have emboli, but only minimal mitral stenosis, anticoagulant treatment might be considered, although this carries its own difficulties and risks. Szekely (1964) reports a reduced incidence of emboli from $9.4 \%$ to $3.4 \%$ per year with anticoagulant treatment. One might also consider removal of the atrial appendage without interfering with the mitral valve as an alternative procedure.

\section{Summary}

A three-year follow-up is reviewed of 84 patients over the age of 40 who had mitral valvotomy at Guy's Hospital.

The immediate mortality of mitral valvotomy was $6 \%$, with a further mortality of $5 \%$ per year during the follow-up.

The results in 34 patients who had had previous systemic emboli showed only $27 \%$ good results in respect of exercise tolerance compared with $47 \%$ in the non-emboli group.

Thirteen patients who had minimal mitral stenosis and were operated on to prevent further emboli also had poor results.

Six of the 84 patients had further emboli at operation and a further four had emboli during the three-year follow-up.

The occurrence of emboli is not thought to be an additional reason for performing mitral valvotomy, and long-term anticoagulant treatment might be used.

We are indebted to Sir Russell Brock, Mr. Donald Ross, and Mr. R. H. F. Brain, who operated on these patients, and to Dr. Charles Baker and Dr. Ralph Kauntze, who allowed us to use their records. We are particularly grateful to Dr. Charles Baker for his advice, help, and contribution to this paper.

\section{REFERENCES}

Baker, C., Brock, R. C., Campbell, M., and Wood, P. (1952). Brit. med. 7., 1, 1043 . - and Hancock, W. E. (1960). Brit. Heart 7., 22, 281.

Bannister, R. G. (1960). Lancet, 2, 329.

Gilchrist, A. R. (1963). Brit. med. F., 1, 209.

Szekely, P. (1964). Ibid., 1, 1209 .

Szekely, P. (1964). Ibid., 1, 1209.

\title{
Studies on Tyrosinosis: 1, Effect of Low-tyrosine and Low-phenylalanine Diet
}

\author{
SVERRE HALVORSEN,* M.D. ; LEIV R. GJESSING, † M.D.
}

Brit. med. F., 1964, 2, 1171-1173

It has repeatedly been stated that no proved case of tyrosinosis has been described since the original report of Medes (1932) on a 49-year-old man with myasthenia gravis who excreted large amounts of $p$-hydroxyphenyl-pyruvic acid, the $\alpha$-keto-acid of tyrosine, in the urine. Sakai and Kitagawa (1957a, 1957b) and Sakai et al. (1959) reported, however, on a child with hepatomegaly, splenomegaly, liver dysfunction, and progressive hypophosphataemic rickets who subsequently died of liver cirrhosis with hepatoma. This child excreted large amounts of p-hydroxyphenyl-lactic acid and moderate amounts of $p$-hydroxyphenyl-pyruvic acid and $p$-hydroxyphenyl-acetic acid together with tyrosine in the urine. The authors postulated a lack of the p-hydroxyphenyl-pyruvate oxidase and reported their patient as an atypical case of tyrosinosis. Since that time similar cases have been reported by Zetterström (1963) and Fritzell et al. (1964).

In June 1963 a 1-year-old girl was admitted to the Children's Department, Rikshospitalet, Oslo, because of hepatomegaly. She was found to have hypophosphataemic rickets, elevated serum-tyrosine level, amino-aciduria with pronounced tyrosine

* Paediatric Research Institute, Rikshospitalet, Oslo.

t Central Laboratory, Dikemark Hospital, Asker, Norway. Financial support from U.S. Public Health Service Grant MH-05726-03, is gratefully acknowledged. excretion, and a large urinary excretion of $p$-hydroxyphenylpyruvic acid, $p$-hydroxyphenyl-lactic acid, and $p$-hydroxyphenyl-acetic acid. The excretion of the tyrosine metabolites was unchanged after loading with vitamin C. Three similar cases have been diagnosed since that time and a detailed report of all these cases will be published elsewhere.

The ultimate proof that this disease is due to a deficiency of p-hydroxyphenyl-pyruvate oxidase is still lacking. Further, the pathogenesis of the liver and kidney dysfunction and of the other symptoms and signs of this disease remains obscure. Nor has any specific therapy been available. It was thought that a trial with a low-tyrosine and low-phenylalanine diet might give an answer to some of these questions, and it is the purpose of the present paper to report briefly the clinical and biochemical findings in our first case and to describe the effects of low-tyrosine and low-phenylalanine diet on the excretion of tyrosine and its metabolites, on the liver and kidney function, and on the general clinical condition of the patient.

\section{Methods}

The serum tyrosine and phenylalanine were determined according to the method of Berry (1962) except that butanol/ 